\title{
Prediction of Laser Cut Quality for Tungsten Alloy Using the Neural Network Method
}

\author{
Simon Klancnik ${ }^{1}$ - Derzija Begic-Hajdarevic 2 ,* - Matej Paulic ${ }^{1}$ - Mirko Ficko ${ }^{1}$ - Ahmet Cekic ${ }^{2}$ \\ - Maida Cohodar Husic ${ }^{2}$ \\ ${ }^{1}$ University of Maribor, Faculty of Mechanical Engineering, Slovenia \\ 2University of Sarajevo, Faculty of Mechanical Engineering, Bosnia and Herzegovina
}

\begin{abstract}
The cut quality is of great importance during the laser cutting process. The quality of laser cut mainly depends on an appropriate selection of process parameters. In this paper, the effect of process parameters was analysed on the laser cut quality of an uncommon alloy, the tungsten alloy ( $W \approx 92.5 \%$ and the remainder Fe and Ni) sheet with thickness of $1 \mathrm{~mm}$. This alloy has a wide application in different industrial areas, e.g. in medical applications, the automobile sectors, and the aircraft industry. This paper introduces a developed back-propagation artificial neural network (BP-ANN) model for the analysis and prediction of cut quality during the $\mathrm{CO}_{2}$ laser cutting process. In the presented study, three input process parameters were considered such as laser power, cutting speed and assist gas type, and two output parameters such as kerf width and average surface roughness. Amongst the 42 experimental results, 34 data sets were chosen for training the network, whilst the remaining 8 results were used as test data. The average prediction error was found to be $5.5 \%$ for kerf width and $9.5 \%$ for surface roughness. The results of the predicted kerf width and surface roughness by the BP-ANN model were compared with experimental data. Based on the results of the study, it was shown that the proposed artificial neural network model could be a useful tool for analysing and predicting surface roughness and kerf width during $\mathrm{CO}_{2}$ laser cutting processes.
\end{abstract}

Keywords: laser cutting, cut quality, artificial neural network, tungsten alloy

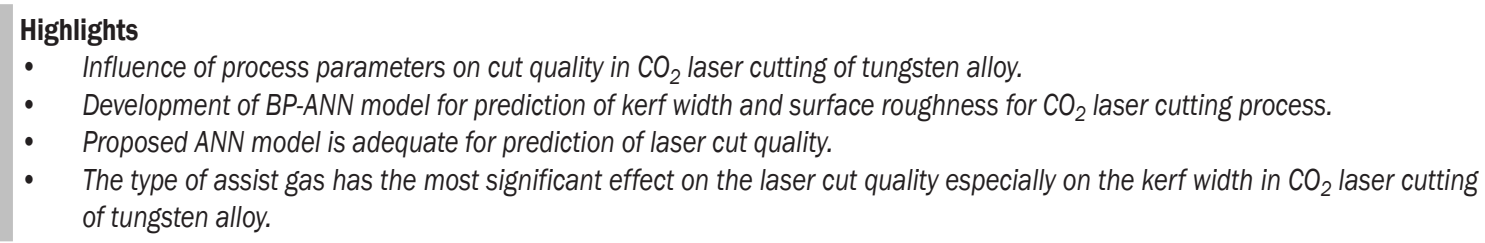

\section{INTRODUCTION}

Laser beam machining is a thermal energy-based advanced machining process during which material is removed by melting and/or vaporisation. Interest in predicting the materials' removal phenomena has existed since the beginning of the exploitation of laser beams for cutting. The laser cutting process can be applied to a wide range of materials using different technological procedures. Modelling based on an analytical solution is usually centred on certain assumptions and is sometimes unable to solve the whole system in practical cases [1]. The focus was firstly on the modelling of the process, which is difficult to model because of the high numbers and substantial varieties of influential parameters. Secondly, attention was focused on the results of cutting such as geometry of kerf and correspondingly cut quality. No general model was established because of the many process parameters and very different physical processes which are present during the laser cutting process. Despite this, users need solutions for predicting possible economic exploitations of the laser cutting process. Artificial neural network, fuzzy expert systems, genetic algorithms are common for the production of machining models [2] to [4]. Artificial intelligence methods mostly use experimental data for generating models [1]. In regard to the cut quality according to the input parameters, the work is going in the direction of researching uncommon materials or analysing the cuttings of different cut shapes such as wedge surfaces. A special point of interest is analysing the cut surface roughness and kerf shape [5].

Further analyses of interest are especially uncommon materials and alloys where the common knowledge is inapplicable [6]. The effects of laser power, cutting speed and oxygen assist gas pressure on the cut qualities in $\mathrm{CO}_{2}$ laser cutting of tungsten alloy were analysed in [7]. Regression analysis has been used for the developments of empirical models able to describe the effects of the process parameters on the $\mathrm{CO}_{2}$ laser cut qualities of the Inconel 718 nickel - based super alloy [8]. In [9] regression models were developed for kerf taper and surface roughness after laser cutting of titanium alloy where the factors are determined by genetic algorithms. The fuzzy expert system was used to predict the laser cut quality of Incoloy alloy 800 , the input parameters 
of the prediction system in [5] are power, assist gas pressure and cutting speed and the output parameters are surface roughness and dross inclusion. Multiple regression analysis is used for predicting the surface roughness and widths of heat-affected zones during the $\mathrm{CO}_{2}$ laser cutting of alloy steels using nitrogen as assist gas [10]. A multiple regression analysis and an artificial neural network are used to predict the depths of the cutting line, widths of heat affected zone and cutting line during the laser cutting of epoxy and copper-compounded epoxy [11]. The predicting model includes three input parameters such as current, frequency and cutting speed. At the end, a genetic algorithm is implemented to optimise the parameters for faster cutting speed and least heat-affected zone. A neural network is introduced to classify the striation patterns of the cut surfaces during $\mathrm{CO}_{2}$ laser cutting of the wedge surfaces [12]. The work is also extended in the modelling and experimenting of laser cutting porous material, correspondingly of aluminum foam [13]. Models for predicting cut quality or kerf shape are based on factorial analysis in [8] or genetic algorithms in [9] and [11], neural networks in [11] and [12] and fuzzy expert systems in [5].

However, we did not find in the literature many studies that had considered the $\mathrm{CO}_{2}$ laser cutting of refractory materials. For this reason, in the presented study, a back-propagation artificial neural network model has been applied for predicting the cut quality during the $\mathrm{CO}_{2}$ laser cutting of tungsten alloy sheet. The important quality characteristics related to laser cutting of sheets are kerf width, surface roughness, heat affected zone [14]. Kerf width and average surface roughness have been considered as quality characteristics in this paper.

Section 1 describes experimental setup, Section 2 presents a BP-ANN-based model for predicting quality characteristics, and Section 3 presents the results and discussion. The conclusion is given in Section 4.

\section{EXPERIMENTAL SETUP}

The experiments were carried out on a Rofin $\mathrm{CO}_{2}$ laser system (model DC020) with a nominal output power of $2000 \mathrm{~W}$ in $\mathrm{CW}$ mode at a wavelength of 10.6 $\mu \mathrm{m}$ with a high quality beam (beam quality factor $K=$ 0.95). The experimental investigations were conducted at the University of Applied Science Jena in Germany. Tungsten alloy $(\mathrm{W} \approx 92.5 \%$ and the remainder $\mathrm{Fe}$ and $\mathrm{Ni}$ ) sheet with thickness of $1 \mathrm{~mm}$ was used for experimentation. The products manufactured of the tungsten alloy sheets have found new possibilities for applications within different industrial areas, e.g. in medical applications, the automobile sectors, and the aircraft industry. The laser beam was focused using a $\mathrm{ZnSe}$ focusing lens with focal length of $127 \mathrm{~mm}$. Diameter of focusing lens was $38.1 \mathrm{~mm}$. The laser spot diameter at the focal point is measured to be about 0.21 $\mathrm{mm}$, it is applied the inclined plane method. Assist gas was used coaxially with the laser beam via a $2 \mathrm{~mm}$ exit diameter nozzle. Focus position, nozzle stand of distance (stand-off) and assist gas pressure were kept constant throughout the main experimentation. The optimal values of these process parameters were selected based on a previous experimental study [15] for each of assist gasses (oxygen, nitrogen and air). A full cut, with an acceptable kerf width, cutting edge striations and dross to a minimum; were the criteria of selecting optimal values of these parameters. Three input process parameters were selected for analysis at the presented study. These are laser power, cutting speed and assist gas type. The working range of cutting speed was selected based on a previous experimental study [15] for each assist gas type and a certain laser power. The range of process parameters utilised is summarised in Table 1. Testing the effect of one parameter on the cut quality requires the variation of one parameter whilst keeping the other two parameters at the pre-selected values.

The controlled parameters were the top surface kerf width and the surface roughness. Visual inspections of each cut were carried out to ensure that no pitting and burrs were present within the cut areas. The sample geometry of the measurements taken are shown in Fig. 1.

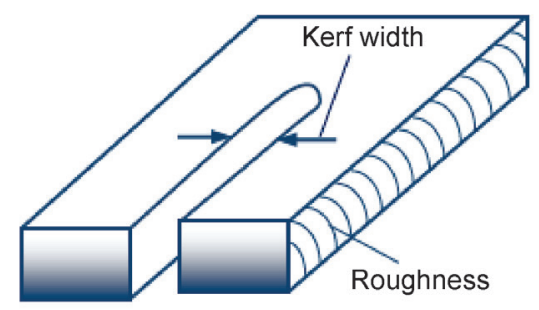

Fig. 1. The sample geometry

Table 1. Input process parameters and their levels used in the experiments

\begin{tabular}{lccccc}
\hline $\begin{array}{l}\text { Assist } \\
\text { gas type }\end{array}$ & $\begin{array}{c}\text { Laser power } \\
\text { [W] }\end{array}$ & $\begin{array}{c}\text { Cutting speed } \\
\text { [mm/min] }\end{array}$ & $\begin{array}{c}\text { Gas } \\
\text { pressure } \\
\text { [bar] }\end{array}$ & $\begin{array}{c}\text { Focus } \\
\text { position } \\
\text { [mm] }\end{array}$ & $\begin{array}{c}\text { Stand- } \\
\text { off } \\
\text { [mm] }\end{array}$ \\
\hline Oxygen & 1500 to 2000 & 3000 to 6000 & 12.5 & -0.5 & 1 \\
\hline Nitrogen & 1500 to 2000 & 1000 to 2250 & 15 & -0.5 & 0.75 \\
\hline Air & 1500 to 2000 & 2000 to 4500 & 15 & -1 & 1 \\
\hline
\end{tabular}


Surface roughness on the cut edge was measured in terms of the average roughness $R_{a}$, using a TaylorHobson stylus instrument. Roughness was measured along the length of a cut approximately in the middle of the thickness. Five consistent surface roughness values of each sample were measured and an average value was calculated for each sample.

The kerf width was measured using a Stemi optical microscope fitted with a video camera and a zoom lens. Kerf width was measured in the microscope images of each sample at five different places and an average value was calculated for each sample.

\section{BACK-PROPAGATION ARTIFICIAL NEURAL NETWORK BASED MODEL}

A multilayer feed-forward neural network with back-propagation algorithm (BP-ANN) was used to model the laser cutting process. BP-ANN is one of the more widely used artificial neural networks. It is constructed of an input layer, output layer and one

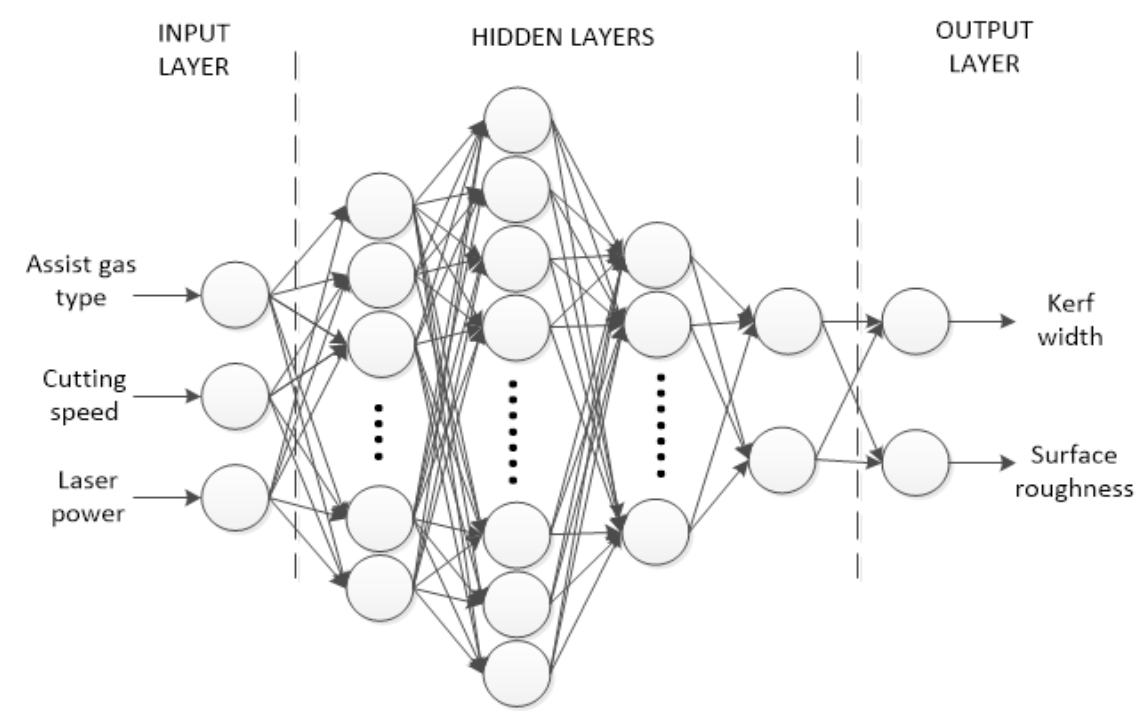

Fig. 2. Back-propagation artificial neural network used for predicting kerf width and surface roughness

Table 2. Experimental data used as training database

\begin{tabular}{|c|c|c|c|c|c|c|c|c|c|c|c|}
\hline No. & $\begin{array}{l}\text { Assist } \\
\text { gas type }\end{array}$ & $\begin{array}{c}\text { Power } \\
{[\mathrm{W}]}\end{array}$ & $\begin{array}{c}\text { Speed } \\
{[\mathrm{mm} / \mathrm{min}]}\end{array}$ & $\begin{array}{c}\text { Kerf } \\
{[\mathrm{mm}]}\end{array}$ & $\begin{array}{c}\mathrm{Ra} \\
{[\mu \mathrm{m}]}\end{array}$ & No. & $\begin{array}{l}\text { Assist } \\
\text { gas type }\end{array}$ & $\begin{array}{c}\text { Power } \\
{[\mathrm{W}]}\end{array}$ & $\begin{array}{c}\text { Speed } \\
{[\mathrm{mm} / \mathrm{min}]}\end{array}$ & $\begin{array}{c}\text { Kerf } \\
{[\mathrm{mm}]}\end{array}$ & $\begin{array}{c}\mathrm{Ra} \\
{[\mu \mathrm{m}]}\end{array}$ \\
\hline 1 & Oxygen & 2000 & 3000 & 0.35 & 7.73 & 18 & Nitrogen & 1750 & 1000 & 0.20 & 5.33 \\
\hline 2 & Oxygen & 2000 & 3500 & 0.34 & 722 & 19 & Nitrogen & 1750 & 1500 & 0.19 & 5.57 \\
\hline 3 & Oxygen & 2000 & 4000 & 0.34 & 7.18 & 20 & Nitrogen & 1750 & 2000 & 0.18 & 6.56 \\
\hline 4 & Oxygen & 2000 & 5000 & 0.29 & 6.01 & 21 & Nitrogen & 1500 & 1000 & 0.17 & 5.82 \\
\hline 5 & Oxygen & 2000 & 6000 & 0.27 & 3.73 & 22 & Nitrogen & 1500 & 2000 & 0.19 & 4.97 \\
\hline 6 & Oxygen & 1750 & 3000 & 0.34 & 7.78 & 23 & Air & 2000 & 2000 & 0.24 & 7.17 \\
\hline 7 & Oxygen & 1750 & 3500 & 0.33 & 8.22 & 24 & Air & 2000 & 3000 & 0.23 & 4.66 \\
\hline 8 & Oxygen & 1750 & 4500 & 0.32 & 6.25 & 25 & Air & 2000 & 3500 & 0.23 & 4.50 \\
\hline 9 & Oxygen & 1750 & 5000 & 0.27 & 7.13 & 26 & Air & 2000 & 4000 & 0.23 & 3.52 \\
\hline 10 & Oxygen & 1750 & 5500 & 0.31 & 5.97 & 27 & Air & 2000 & 4500 & 0.23 & 2.77 \\
\hline 11 & Oxygen & 1500 & 3000 & 0.35 & 7.75 & 28 & Air & 1750 & 2000 & 0.24 & 5.46 \\
\hline 12 & Oxygen & 1500 & 3500 & 0.32 & 7.58 & 29 & Air & 1750 & 2500 & 0.23 & 3.95 \\
\hline 13 & Oxygen & 1500 & 4000 & 0.29 & 6.79 & 30 & Air & 1750 & 3000 & 0.23 & 3.80 \\
\hline 14 & Oxygen & 1500 & 4500 & 0.28 & 6.02 & 31 & Air & 1750 & 4000 & 0.23 & 3.77 \\
\hline 15 & Nitrogen & 2000 & 1000 & 0.20 & 5.41 & 32 & Air & 1500 & 2000 & 0.24 & 5.24 \\
\hline 16 & Nitrogen & 2000 & 1500 & 0.19 & 5.92 & 33 & Air & 1500 & 3000 & 0.22 & 4.04 \\
\hline 17 & Nitrogen & 2000 & 2250 & 0.19 & 7.14 & 34 & Air & 1500 & 3500 & 0.23 & 2.76 \\
\hline
\end{tabular}


or more hidden layers. Using a back-propagation algorithm, the weights and biases were adapted to minimise the mapping error.

In the presented study, the neural network was used with an input layer having three neurons, four hidden layers with 8-15-5-2 number of neurons in each of the hidden layers and an output layer with two neurons, as shown in Fig. 2. This configuration was found to be the most suitable network architecture with the lowest mean prediction error [\%] for our problem. The appropriate architecture for the artificial neural network was selected through an exhaustive examination of a number of network configurations. This was accomplished by changing the number of hidden layers and number of neurons in the hidden layer. Three input variables, namely: assist gas type

Table 3. Experimental data used as testing database

\begin{tabular}{clcccc}
\hline No. & $\begin{array}{c}\text { Assist gas } \\
\text { type }\end{array}$ & $\begin{array}{c}\text { Power } \\
{[\mathrm{W}]}\end{array}$ & $\begin{array}{c}\text { Speed } \\
{[\mathrm{mm} / \mathrm{min}]}\end{array}$ & $\begin{array}{c}\text { Kerf } \\
{[\mathrm{mm}]}\end{array}$ & $\begin{array}{c}\mathrm{Ra} \\
{[\mu \mathrm{m}]}\end{array}$ \\
\hline 1 & 0xygen & 2000 & 4500 & 0.31 & 6.14 \\
\hline 2 & 0xygen & 2000 & 5500 & 0.27 & 4.49 \\
\hline 3 & 0xygen & 1750 & 4000 & 0.32 & 6.80 \\
\hline 4 & Nitrogen & 2000 & 2000 & 0.18 & 6.23 \\
\hline 5 & Nitrogen & 1500 & 1500 & 0.18 & 5.41 \\
\hline 6 & Air & 2000 & 2500 & 0.24 & 4.92 \\
\hline 7 & Air & 1750 & 3500 & 0.22 & 3.33 \\
\hline 8 & Air & 1500 & 2500 & 0.23 & 3.30 \\
\hline
\end{tabular}

(oxygen, nitrogen or air), laser power [W] and cutting speed $[\mathrm{mm} / \mathrm{min}]$ and two output variables namely: surface roughness $[\mu \mathrm{m}]$ and kerf width $[\mathrm{mm}]$ are used in the developed model, see Fig. 2. Experimental data were used to train the network. Amongst the 42 experimental results, 34 data sets were chosen for training the network (Table 2), whilst the remaining 8 results were used as test data (Table 3). All the data sets variables were normalised between 0 and 1 , except for assist gas where the values were for Oxygen 0, Nitrogen 0.5 and for Air 1.

\section{RESULTS AND DISCUSSION}

In order to assess the network properly only 116 epochs of learning were sufficient for training. The network should be learnt to approximate but not to fit exactly the showed pattern just in the case of predicting future reliable results when the range of the input signals changes slightly. That is the reason why the number of training epochs should not be too high.

During the network learning the neurons covered various activated positions. Some neurons were activated more than others. The changes in activities of the neurons were important because they showed the behaviour of the network and the different values of the connections' weights. The higher was the value of the weight the stronger the influences and impacts on the neuron. In the created network the bias value

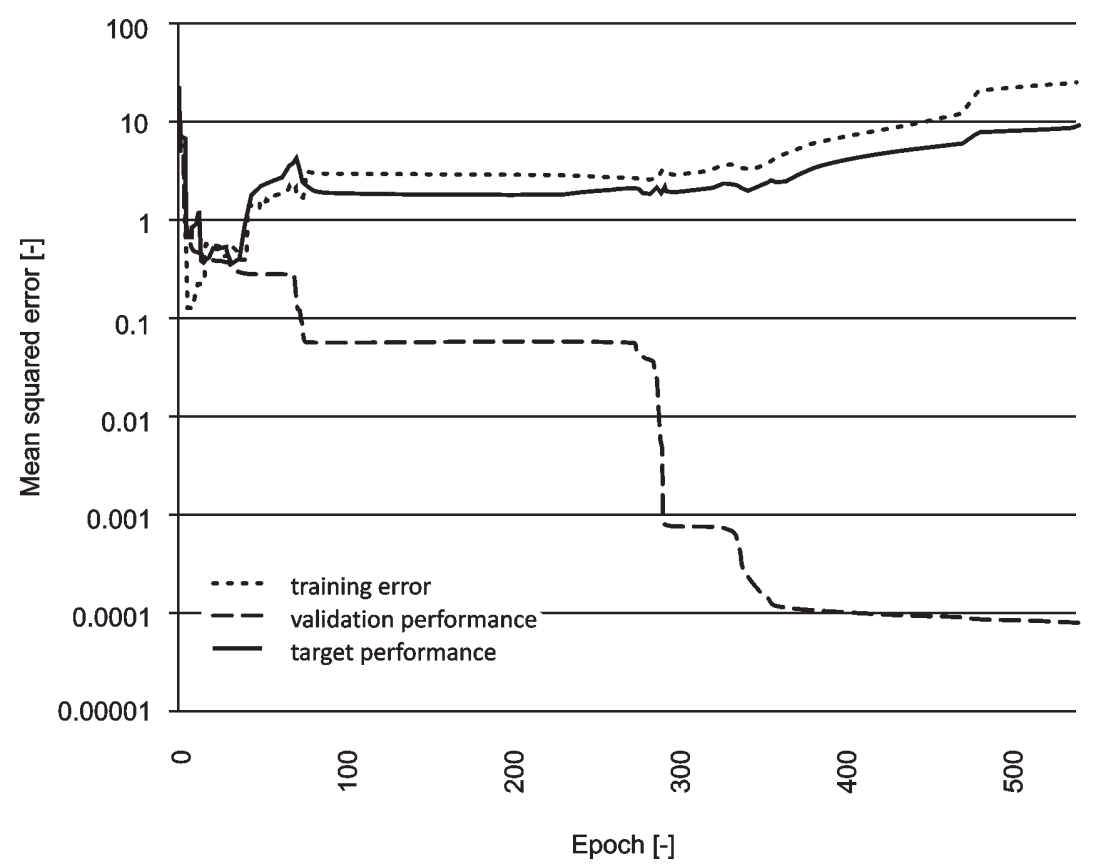

Fig. 3. Training performance of BP-ANN 
was very important when relating to the training process. Bias is a neuron in which the activation function is permanently set at 1 . Just as with other neurons, a bias connects to the neurons in the layer above via a weight which is often called threshold.

Despite the fact that the size of the training data set is not very large (34 samples) the performance of the BP-ANN whilst training was good, as shown in Fig. 3. The results of BP-ANN modelling (learning training) are displayed in Figs. 4 and 5.

The modelling seemed to be quite promising when we were concerned that the average training error of kerf width was $3.69 \%$ and the average training error of surface roughness was $4.45 \%$. In the prediction step the dispersion between experimental and predicted values was quite small. The average prediction error of kerf width was $5.5 \%$ and the average prediction error of surface roughness was smaller than $10 \%$. The results of BP-ANN predictions for each test sample are shown in Figs. 6 and 7.

\section{CONCLUSION}

In the presented study, artificial neural network was used for predicting kerf width and surface roughness during the $\mathrm{CO}_{2}$ laser cutting of tungsten alloy sheet. It is evident that the prediction error of kerf width is smaller than the prediction error of surface roughness

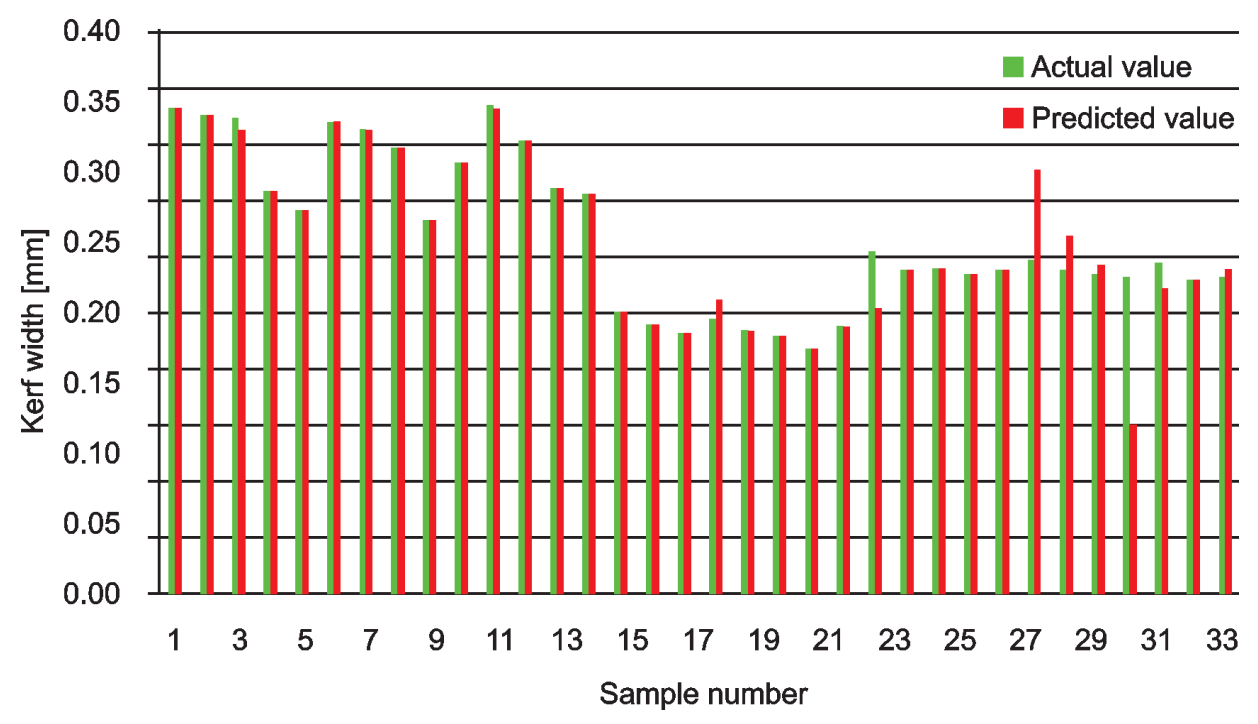

Fig. 4. Actual and predicted values of BP-ANN training for kerf width

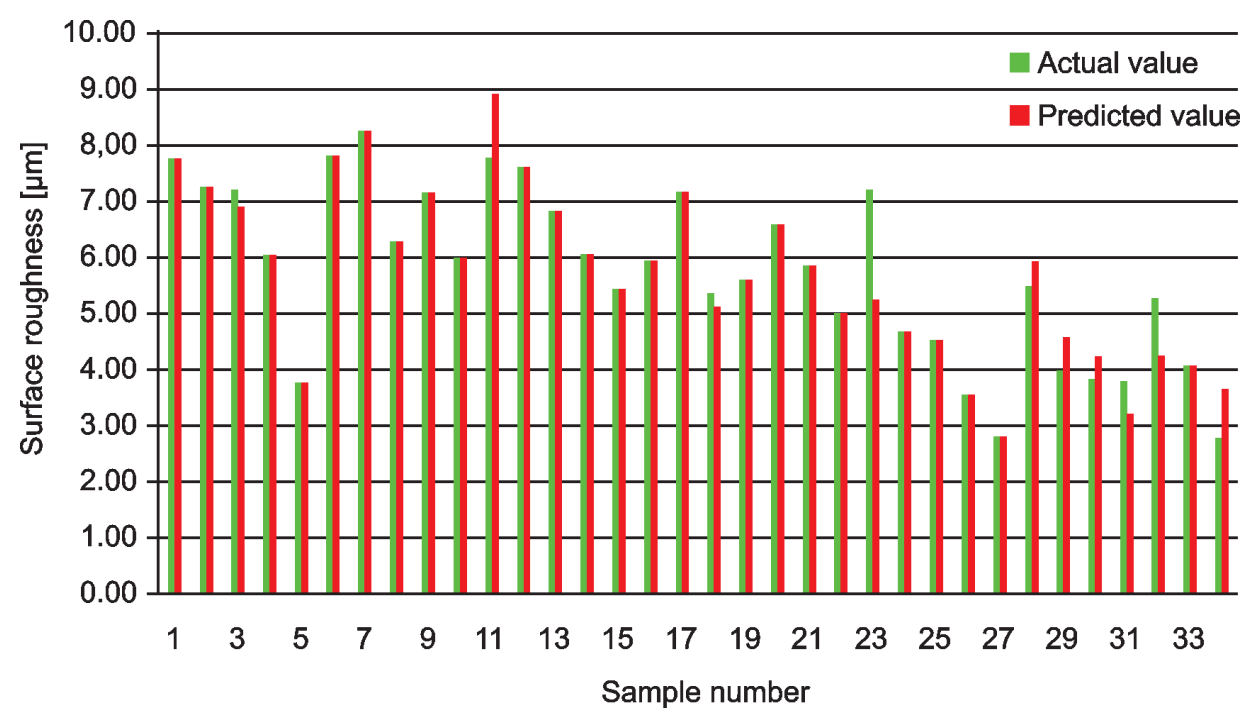

Fig. 5. Actual and predicted values of BP-ANN training for surface roughness 


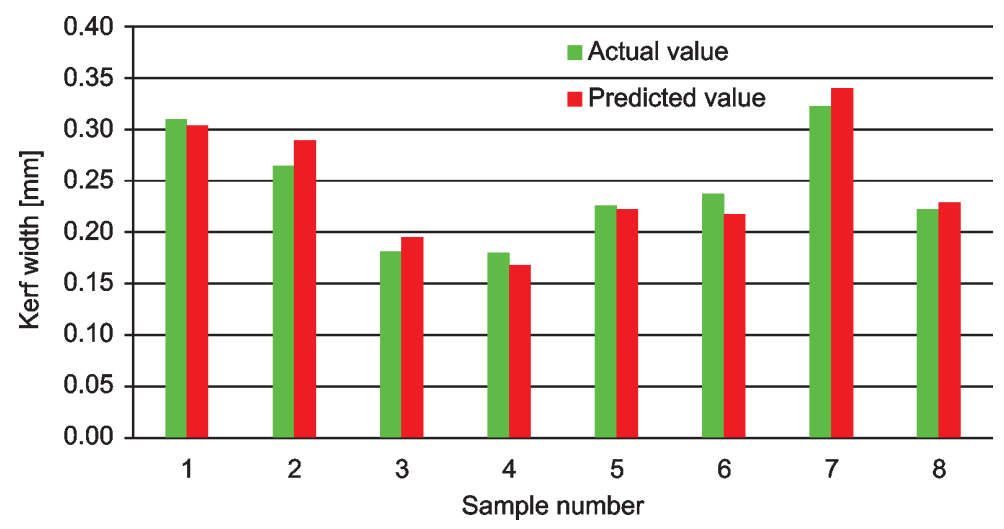

Fig. 6. Actual and predicted values of BP-ANN testing for kerf width

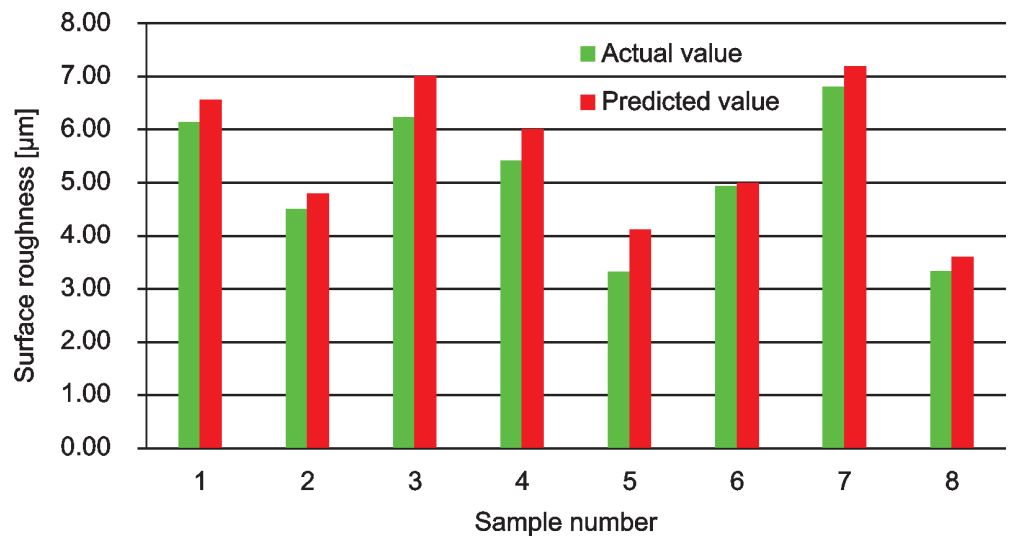

Fig. 7. Actual and predicted values of BP-ANN testing for surface roughness

but it can be concluded that the ANN model is adequate for predicting both of these laser cutting processes' performances.

In this work, it was also shown that in the field of experimental research the assist gas type has the most significant effect on the cut quality especially on the kerf width. The ability to predict cut quality even before machining based on the input process parameters such as laser power, cutting speed and assist gas type would give manufacturers the benefits in terms of cost and time savings and the possibility of selecting the appropriate laser cutting process parameters in order to obtained optimal quality characteristics.

In practice when we are cutting rare or even unknown material we need to obtain the input parameters, which will result in sufficient quality. The presented work enables possibility to get those parameters with fewer experiments and without need to analyse all possible mutual influences. In the future work, more detailed discussions should be considered on the effects of different process parameters such as assist gas pressure, focus position, stand-off, type material and material thickness on laser cutting quality characteristics such as heat-affected zone, microstructure and micro-hardness.

\section{ACKNOWLEDGEMENT}

The authors would like to thank the Ministry of Education, Science and Sport, Republic of Slovenia and the Federal Ministry of Education and Science, Bosnia and Herzegovina for their financial support of this study through the Bilateral Project entitled: "Development of an intelligent system for prediction of $\mathrm{CO}_{2}$ laser cut quality". Also, thanks to the Department of Laser and Opto-Technologies at the University of Applied Science Jena, Germany where experimental work was performed.

\section{REFERENCES}

[1] Parandoush, P., Hossain, A. (2014). A review of modeling and simulation of laser beam machining. International Journal of Machine Tools and Manufacture, vol. 85, p. 135-145, D0I:10.1016/j.ijmachtools.2014.05.008. 
[2] Klancnik, S., Brezocnik, M., Balic, J., Karabegovic, I. (2013). Programming of CNC milling machines using particle swarm optimization. Materials and manufacturing processes, vol. 28, no. 7, p. 811-815, Dol:10.1080/10426914.2012.718473.

[3] Hrelja, M., Klancnik, S., Balic, J., Brezocnik, M. (2014). Modelling of a turning process using the gravitational search algorithm. International Journal of Simulation Modelling, vol. 13, no. 1, p. 30-41, Dol:10.2507/IJSIMM13(1)3.248.

[4] Ficko, M., Palcic, I. (2013). Designing a layout using the modified triangle method, and genetic algorithms. International Journal of Simulation Modelling, vol. 12, no. 4, p. 237-251, D0I:10.2507/IJSIMM12(4)3.244.

[5] Syn, C.Z., Mokhtar, M., Feng, C.J., Manurung, Y.H.P. (2011). Approach to prediction of laser cutting quality by employing fuzzy expert system. Expert Systems with Applications, vol. 38, no. 6, p. 7558-7568, D0I:10.1016/j.eswa.2010.12.111.

[6] El-Labban, H.F., Mahmoud, E.R.I., Al-Wadai, H. (2014). Laser cladding of Ti-6Al-4V alloy with vanadium carbide particles. Advances in Production Engineering \& Management, vol. 9, no. 4, p. 159-167, D0l:10.14743/apem2014.4.184.

[7] Begic, D., Kulenovic, M., Cekic, A., Bliedtner, J. (2009). CW CO2 laser cutting of tungsten alloy using 02 assist gas. Proceedings of the 20th International DAAAM Symposium, $\mathrm{p}$. 1345-1346.

[8] Hasçalık, A., Ay, M. (2013). CO2 laser cut quality of Inconel 718 nickel-based superalloy. Optics \& Laser Technology, vol. 48, p. 554-564, D0I:10.1016/j.optlastec.2012.11.003.

[9] Pandey, A.K., Dubey, A.K. (2012). Simultaneous optimization of multiple quality characteristics in laser cutting of titanium alloy sheet. Optics \& Laser Technology, vol. 44, no. 6, p. 18581865, D0l:10.1016/j.optlastec.2012.01.019.

[10] Cekic, A., Begic-Hajdarevic, D., Kulenovic, M., Omerspahic, A. (2014). $\mathrm{CO}_{2}$ laser cutting of alloy steels using $\mathrm{N}_{2}$ assist gas. Procedia Engineering, vol. 69, p. 310-315, Dol:10.1016/j. proeng.2014.02.237.

[11] Tsai, M.-J., Li, C.-H., Chen, C.-C. (2008). Optimal lasercutting parameters for QFN packages by utilizing artificial neural networks and genetic algorithm. Journal of Materials Processing Technology, vol. 208, no. 1-3, p. 270-283, D0I:10.1016/J.jmatprotec.2007.12.138.

[12] Yilbas, B.S., Karatas, C., Uslan, I., Keles, O., Usta, Y., Yilbas, Z., Ahsan, M. (2008). Wedge cutting of mild steel by $\mathrm{CO} 2$ laser and cut-quality assessment in relation to normal cutting. Optics and Lasers in Engineering, vol. 46, no. 10, p. 777-784, D0l:10.1016/j.optlaseng.2008.04.019.

[13] Yilbas, B.S., Akhtar, S., Keles, O. (2014). Laser cutting of triangular blanks from thick aluminum foam plate: Thermal stress analysis and morphology. Applied Thermal Engineering, vol. 62, no. 1, p. 28-36, D0l:10.1016/j. applthermaleng.2013.09.026.

[14] Avanish, K.D., Vinod, Y. (2008). Laser beam machining - A review. International Journal of Machine Tools \& Manufacture, vol. 48, no. 6, p. 609-628, D0l:10.1016/j. ijmachtools.2007.10.017.

[15] Begic, D. (2010). Experimental and Numerical Analysis of Influential Parameters on the Cut Quality in Metal Laser Cutting. PhD thesis, University of Sarajevo, Sarajevo. 